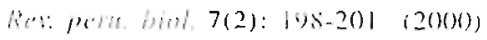

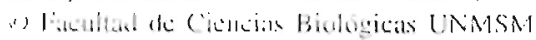

ISSN 1561-0837

\title{
El "erizo de mar" Tetrapygus niger como marcador biológico de estrés oxidativo
}

\author{
Sea urchin Tetrapigus niger as a biological marker of oxidative stress *
}

\author{
Doris Huerta Canales, Raquel Orć Sifuentes y Marco Núñez Fonseca
}

\begin{abstract}
In this research the sea urchin Tetrapigus Niger has been used as a model to study oxidative stress to measure the lipid peroxidation in sperm nuclei. Oxidative stress was observed in sperm nuclei with and without hydrogen peroxide, which is a good free radicals generating system
\end{abstract}

Key words: Oxidative stress, lipid peroxidation, Tetrapigus Niger, hydrogen peroxide.

Todos estamos expuestos a la radiación electromagnética ranto náturáal como artificial. La radiación divide el agua del cuerpo generando radicales hidroxilo $(\mathrm{OH}$ )altamente reactivos que frecuentemente dejan tras sí una secuencia en cadena de radicales libres en propagación. El cuerpo produce otro radical de oxígeno, el superóxido $\left(\mathrm{O}_{2}{ }^{\prime}\right)$. Aproximadamente el $3 \%$ de oxígeno que respiramos es usado para producil $\mathrm{O}_{2}$, produciendo más de $2 \mathrm{~K}$ de $\mathrm{O}_{2}$ "en el cuerpo cada año y las personas con infecciones crónicas pueden producir aún más.

Los radicales libres de oxígeno (OFR ) son potencialmente muy tóxicos para las células, y debido a su naturaleza altamente reactiva son moléculas o átomos catiónicos, aniónicos o neutros que pueden fácilmente combinarse con otras moléculas, tales como enzimas, receptores, bombas iónicas, causando su oxidación directamente e inhibiendo su normal funcionamiento. Algunos de los productos de ataque de los OFR pueden interferir con el funcionamiento del DNA (Halliwell y Auroma,

Centro de Investigación de Bioquimica y Nutrición (CIBN) Facultad de Medicina, Universidad Nacional Mayor de San Marcos - Subvencion? FEDU 97
1991; Beckmam y Bruce, 1997; (generar alteraciones en la secuencia de bases con el potencial para mulaciones, que en casos extremos conduce a situaciones patológicas): puede cambiar las proteinas, generando nuevas estructuras inmunogénicas. Los OFRs son definidos como especies químicas que poseen uno o más electrones desápareados y son palte de un grupo de moléculas denominadas especies reactivas de oxigeno (ROS) que se originan de varias maneras, principalmente por reacciones redox que involucran al oxígeno y que se produce como parte del metabolismo normal, por ejm. $\mathrm{O}_{2} *$, $\mathrm{NO}^{*}, \mathrm{H}_{2} \mathrm{O}_{2}$ (Halliwell B., 1991).

En respuesta a la exposición de radiación UV. contaminación ambiental, humo de cigarrillo, ejercicio excesivo, isquemia: $\mathrm{O}_{2}^{*}, \mathrm{OH} I^{*}, \mathrm{ROO} *$, Así, el ladical OH* es altamente reactivo y ataca a moléculas biológicas; el radical superóxido $\left(\mathrm{O}_{2}{ }^{*}\right)$ viaja a través de la sangre actuando como vasodilatador, interviene en la regulación del crecimiento y en señales intracelulares. El óxido nítrico (NO*) (Beckman y cols., 1990) actúa en las células de los músculos lisos. causa relajación de las paredes de los vasos 
sanguíneos. El radical peróxido $\left(\mathrm{H}_{2} \mathrm{O}_{2}\right)$ atraviesa fácilmente las membranas celulares y puede causar la expresión de genes virales. Uno de sus efectos más destructivos es la iniciación de lipoperoxidación, que conduciría a la destrucción de la membrana celular. Un radical puede extraer un hidrógeno de un ácido graso poliinsaturado en la membrana celular y generar un dieno conjugado, el cual después de un rearreglo, fácilmente se combinaría con el oxígeno para dar un radical peroxil-lipídico (iniciación); este en una segunda vuelta puede extraer un hidrógeno a partir de otro ácido graso poliinsaturado (propagación) para dar un hidroperóxido lipídico y un nuevo radical lipídico que luego repite la cadena de eventos. Si no termina esta cadena de reacciones se llegaría a la destrucción de las membranas celulares, ruptula de compartimientos y liberación de enzimas lisosomales y posterior autolisis. Esta reacción en cadena genera moleculas inestables responsables de la aparición de enfermedades degenerativas: cáncer, artritis, diabetes, el proceso de envejecimiento (Halliwell, B., 1995). La terminación de esta cadena de eventos es posible debido a la participación de sistemas antioxidantes que destruyen los radicales libres producidos. Normalmente en la célula están presentes, en gran número y diversidad, los antioxidantes, tales como vitamina $C$, que actúa a nivel citosólico; la vitamina $\mathrm{E}$, cuya acción es a nivel de membrana; la glutation que protege tanto al citosol como a la membrana del ataque de los radicales libres. Otros antioxidantes presentes son las enzimas, como glutation peroxidasa (GPX), glutation reductasa, glutation transferasa, catalasa (hidrolisa el peroxido a oxígeno y agua) y la enzima superóxido dismutasa ( $S O D$ ), que convierte el radical superóxido en peróxido de hidrógeno.

Otros antioxidantes importantes incluyen carotenoides y ubiquinonas. Esta vasta red de defensas antioxidantes intracelulares y extracelulares es una prueba convincente de que los OFRs son producidos en condiciones fisiológicas normales y que sus niveles pueden ser fuertemente regulados para la supervivencia ce'l..lar.

1:l objetivo del presente trabajo ha sido utilizar al erizo como modelo para evaluar el estrés oxidativo ( $E O O)$ miriendo lipoperoxidación en núcleos de espermatozoides.

El material biológico que se usó fue erizos de mar $T$. niger, recolectados en la playa de San Bartolo, Lima, durante los meses de marzo a julio en cantidades que van de 100 a 150 erizos por colecta.

Ll esperma del erizo de mar fue extraído por inyección celómica de $1 \mathrm{~mL}$ de $\mathrm{KCl}$ 0,5 $\mathrm{mol} / \mathrm{L}$ y lavado con agua de mar filtrada; luego se lavó varias veces con $\mathrm{NaCl} 0,15 \mathrm{~mol} / \mathrm{L}$, hasta obtener el pellet limpio centrifugando a 3500 rpm por 10 minutos; en algunos casos se irabajo fresco y cu otros se congcló. Los núcleos fueron extraídos a partir de pellet y homogenizados en buffer $\mathrm{A}$ : Tris $\mathrm{HCl} 10 \mathrm{mmol} /$ L pH 7,5, sucrusa 0,25 mol/L, $\mathrm{MgCl}_{2} 10 \mathrm{mmol}$ $\mathrm{L}, \mathrm{CaCl}_{2} 3 \mathrm{mmol} / \mathrm{L}$, Cloruro de benzamidina $50 \mathrm{mmo} / \mathrm{I}$. se centrifugó a $3500 \mathrm{rpm} \times 10$ min. Se lisó en buffer A con Tritón X 100 , $0,1 \%$; se centrifugó, resuspendió en Tris $\mathrm{HCl}$ $10 \mathrm{mmol} / \mathrm{L} \mathrm{pH} \mathrm{8,} \mathrm{NaCl} 0,15 \mathrm{~mol} / \mathrm{L}, \mathrm{CaCl}_{2} 0,5$ $\mathrm{mmol} / \mathrm{L}, \mathrm{PMSF} 2 \mathrm{mmol} / \mathrm{L}$. Para cl aislamiento de núcleos se utilizó el método del colchón de sucrosa centrifugando a $5000 \mathrm{rpm}$ por $5 \mathrm{~min}$. se urabajo con el pellet. La lipoperoxidación se determinó midiendo la formación de malondialdehido (MDA): A 0,3 mL de muestra se agregó $0,6 \mathrm{~mL}$ de TCA $20 \mathrm{~g} / \mathrm{dL}$, se hirvió en baño María duräatre 10 min. se enfrió y se agregó TBA (Ácido Tiobarbitúrico) 0,67g/dL en HCl 0,09 mL. Se hirvió en baño María 30 min. se centrilugí a $3500 \mathrm{rpm}$ durante $5 \mathrm{~min}$, se enfrió y midió la absorbancia a $535 \mathrm{~nm}$.

Utilizando el coeficiente úe extinción para $\mathrm{MDA}=156000 \mathrm{M}$. Se agregó $10 \mathrm{mmol} / \mathrm{L}$ de $\mathrm{H}_{2} \mathrm{O}_{2}$, se incubó durante $30 \mathrm{~min}$. a $37^{\circ} \mathrm{C}$, se midió la variación de formación de MDA a 
diferentes concentraciones de $\mathrm{H}_{2} \mathrm{O}_{2}$ y en función del tiempo.

Hay muchas maneras de estudiar y medir radicales libres, pero todos coinciden con los principales problemas asociados a su alta reactividad, principalmente su vida media relativamente corta, lo que dificulta su medición

La evaluación del estrés oxidativo (EO) su realizó cleterminando lipoperoxidación, siendo el indicador usado la formación de un producto secundario, el complcjo coloreado del malondialdehido (MDA) (Buege y col., 1978).

En la reacción de lipoperoxidación una molécula de MDA reacciona con 2 moléculas: de TBA producicndo un cromógeno rosado con un máximo de absorción entre 532-535nm. Los resultados obtenidos fueron expresados en mg de proteína vial considerando además el peso del pellet de esperma.

Indujimos peroxidación lipídica con concentraciones crecientes de $\mathrm{H}_{2} \mathrm{O}_{2}$ como 10 . 20,50 y $100 u \mathrm{~mol} / \mathrm{L}$ (Tabla 1 ) observando que con $20 \mu \mathrm{mol} / \mathrm{L}$ de $\mathrm{H}_{2} \mathrm{O}_{2}$ se obtienen la mayor formación de MDA. y a concentraciones mayores de $100 \mu \mathrm{mol} / \mathrm{L}$ la lipoperoxidación desciende notablemente, lo que concuerda con lo reportado por Cochrane (199l). Ello podría deberse a un efecto de saturación, es decir, se ha llegado a formar una concentración de hidroperóxidos lipídicos en tal magnitud que destruyen la membrana y escapan de ella para producir alteraciones a di tancia, o podríamos pensar que estos productos de radicales libres se degradan causando interlerencias que impiden su medición. También se evalúo la lipoperoxidación con concentración constante de $\mathrm{H}_{2} \mathrm{O}_{2}$ de $10 \mu \mathrm{mol} / \mathrm{L}$ variando los liempos $(0,15,30,60$ y $120 \mathrm{~min})$. Los resultados observados en la Tabla 2 muestran mayor formauión de MDA a los 60 min, luego comienza a descender, pero a los 15 min. ya hay formación de MDA. Algunos autores reportan que a los $5 \mathrm{~min}$. de incubación ya hay lipoperoxidación. El descenso podría deberse a una inestabilidad del cromógeno para dicho tiempo. Los valores obtenidos para las muestras de núcleo control sin $\mathrm{H}_{2} \mathrm{O}_{2}$ están en el rango de 3,54-3,69 $\times 10^{-6} \mathrm{~mol} / \mathrm{L}$ de MDA, lo que significaría que los efectos de radicales libres se deberían a contaminantes del medio acuático. La bibliografía consultada no reporta valores normales para el erizo de mar, pero sí en el caso de ciertas enfermedades, por ejm.

Tabla 1. Variación de la Concentración de MDA en Función de Concentraciones Crecientes de $\mathrm{H}_{2} \mathrm{O}_{2}$ Incubados a $37^{\circ} \mathrm{C}$ por $30 \mathrm{~min}$

\begin{tabular}{cccccc}
\hline & D. O. & {$\left[\mathrm{H}_{2} \mathrm{O}_{2}\right] \mathrm{mM}$} & $\begin{array}{c}{[\mathrm{MDA}]} \\
10^{-6} \mathrm{M}\end{array}$ & $\begin{array}{c}\text { [MDA] } \\
10^{-9} \mathrm{M} / \mathrm{g} \text { pellet }\end{array}$ & $\begin{array}{c}\text { [MDA] } \\
10^{-11} \mathrm{M} / \mathrm{mg} \text { PT }\end{array}$ \\
\hline Control & 0,092 & 0 & 3,54 & 8,45 & 4,04 \\
1 & 0,103 & 10 & 3,96 & 9,45 & 4,52 \\
2 & 0,153 & 20 & 5,89 & 14,1 & 6,72 \\
3 & 0,155 & 50 & 5,97 & 14,2 & 6,80 \\
4 & 0,130 & 100 & 4,99 & 11.9 & 5,69 \\
\hline
\end{tabular}


diabetes: (control) de 3 a 5 uM y de 5 a 9 uM en pacientes diabéticos.

En conclusión, hemos determinado los valores normales de MDA en el erizo de mar, y como lo menciona la bibliografía el peróxido de hidrógeno es un buen sistema generador de radicales libres como se muestra en las tablas, ya sea que se incremente su concentración o el tiempo de incubación.

\section{Tabla 2. Formación de MDA por Lipoperoxidación en Función del tiempo con concentración $10 \mu \mathrm{M}$ de $\mathrm{H}_{2} \mathrm{O}_{2}$ a $37^{\circ} \mathrm{C}$}

\begin{tabular}{|c|c|c|c|c|c|}
\hline & $\begin{array}{l}\text { Tiempo } \\
\text { min }\end{array}$ & D. 0. & $\begin{array}{l}{[\mathrm{MOA}]} \\
10^{-6} \mathrm{M}\end{array}$ & $\begin{array}{c}{[\mathrm{MDA}]} \\
10^{-9} \mathrm{M} / \mathrm{gpellet}\end{array}$ & $\begin{array}{l}{[\mathrm{MDA}]} \\
10^{-11} \mathrm{M} \mathrm{mg} \mathrm{PT}\end{array}$ \\
\hline Control & 0 & 0,096 & 3,690 & 8,81 & 4,21 \\
\hline 1 & 15 & 0,120 & 4,619 & 11,00 & 5,26 \\
\hline 2 & 30 & 0,215 & 8,280 & 19,80 & 9,45 \\
\hline 3 & 60 & 0,480 & 18,48 & 44,10 & 21,10 \\
\hline 4 & 120 & 0,386 & 14,82 & 35,40 & 16,90 \\
\hline
\end{tabular}

\section{LITERATURA CITADA}

Beckman, J. S, and col. 1990. Proc. Natl. Acad. Sci. USA. 87:1620.

Beckman, K. and Bruce A. 1997. JBC. 272: (32) $19633-36$.

Buege, J. A. and Aust, S. D. 1978. Methods in Enzymology 52: 302-310.

Cochrane, Charles G. 1991. The American Joumal of Medicine. Vol. 91 (suppl 3C): $23 \mathrm{~S}-30 \mathrm{~S}$.

Halliwell, B. and Gtteridge, JMC, 1984. Biochem. J., 219: 1-4.
Halliwell, Barry. 1991. The American Journal of Medicine, Vol. 91 (suppl 3C): 14S-22S.

Halliwell B. and Auroma, OI. 1991. DNA Damage by Oxygen Derived Species. Its Mechanism and Measurement in Mammalian System. FEBS Lett.: 281: 9- 19.

Halliwell B. 1995. Ann. Rheum. Dis.54:505. 